\title{
Managing pregnancy in chronic kidney disease: improving outcomes for mother and baby
}

\author{
This article was published in the following Dove Press journal: \\ International Journal of Women's Health \\ 14 July 2016 \\ Number of times this article has been viewed
}

\author{
Alyssa Fitzpatrick' \\ Fadak Mohammadi ${ }^{2}$ \\ Shilpanjali Jesudason ${ }^{1-3}$ \\ 'Women's and Babies Division, \\ Women's and Children's Hospital, \\ ${ }^{2}$ Central and Northern Adelaide \\ Renal and Transplantation Service, \\ Royal Adelaide Hospital, ${ }^{3}$ Department \\ of Medicine, University of Adelaide, \\ Adelaide, South Australia, Australia
}

Correspondence: Shilpanjali Jesudason Central and Northern Adelaide Renal and Transplantation Service (CNARTS), Level 9, East Wing,

Royal Adelaide Hospital, Adelaide 5000,

South Australia, Australia

Tel +6I 882220900

Fax +6I 882225907

Email shilpa.jesudason@sa.gov.au

\begin{abstract}
Parenthood is a central focus for women with chronic kidney disease, but raises important fears and uncertainties about risks to their own and their baby's health. Pregnancy in women with background kidney disease, women receiving dialysis, or those with a functioning kidney transplant poses a challenging clinical scenario, associated with high maternal-fetal morbidity and potential impact on maternal renal health. Improvements in care over recent decades have led to a paradigm shift with cautious optimism and growing interest regarding pregnancies in women with chronic kidney disease. In this review, we discuss obstetric and renal outcomes, and practical aspects of management of pregnancy in this complex cohort.
\end{abstract}

Keywords: renal, obstetric, fetal, transplant, drugs

\section{Pregnancy and the kidney}

The prevalence of chronic kidney disease (CKD) is rising, and may affect $3 \%$ of women in their childbearing years. ${ }^{1}$ Preexisting CKD of any stage impacts upon maternal and perinatal outcomes. The challenging nature of these pregnancies underscores the need for careful prepregnancy planning in known CKD patients, early identification of new-onset maternal CKD, management of pregnancy with shared decision making, and a patient-centered approach, in an integrated specialized obstetric and nephrology service. This review provides an overview of key issues in clinical management for women with CKD and their infants and discusses strategies for preconception counseling for those planning pregnancy.

\section{Physiological changes in pregnancy}

Pregnancy increases renal workload due to marked anatomical and physiological changes occurring from early gestation. The glomerular filtration rate (GFR) increases by $\sim 50 \%$, with commensurate fall in serum creatinine secondary to plasma volume expansion, renal vasodilation, hyperfiltration, and heightened glomerular basement membrane permeability. Renal adaptations in pregnancy have been explored comprehensively by Odutayo and Hladunewich, ${ }^{2}$ and will not be further described.

Of importance, the physiological changes of pregnancy may unmask or worsen preexisting renal disease. Failure of serum creatinine to fall during pregnancy may indicate underlying renal disease - indeed, levels of creatinine $>90 \mu \mathrm{mol} / \mathrm{L}$ should be considered pathological in pregnancy. ${ }^{3}$ Proteinuria is a hallmark feature of renal disease, but urine protein excretion of up to $300 \mathrm{mg} /$ day may be observed in normal pregnancy. ${ }^{4}$

\section{Defining CKD in pregnancy}

Due to these physiological shifts in the typical markers of CKD (serum creatinine and urine protein), defining $\mathrm{CKD}$ in pregnancy is difficult. In the nonpregnant state, the 
widely used Kidney Disease Outcomes Quality Initiative staging system (Table 1) broadly defines CKD. Commonly used formulae to estimate creatinine clearance or estimated GFR (eGFR) are inaccurate in pregnancy. This includes the Cockroft-Gault and Modification of Diet in Renal Disease formulae. The Cockroft-Gault overestimates GFR, while in preeclampsia, the Modification of Diet in Renal Disease formula underestimates GFR compared with 24-hour creatinine clearance. ${ }^{5}$ Twenty-four-hour urine collections for inulin or creatinine clearance remain the gold standard for GFR measurement, but are clinically impractical and rarely needed, hence our ongoing reliance on serum creatinine. ${ }^{6}$ The heterogeneous classification of CKD in pregnancy studies contributes to underrecognition and uncertainties around diagnosis.

Renal biopsy is reserved for situations where accurate histological diagnosis will substantially change clinical management during pregnancy. A synthesis of studies containing 197 biopsies in total (for diverse indications including preeclampsia) revealed major and minor complications in $2 \%$ and $5 \%$ of cases, respectively, peaking in later pregnancy (after 25 weeks). ${ }^{7}$ Therefore, biopsy should be used judiciously and is rarely indicated to differentiate preeclampsia and renal disease.

\section{Epidemiology of CKD in pregnant populations}

Few studies have explored the population prevalence of CKD in pregnancy. A Norwegian population study provides the best data, suggesting CKD affects $3.3 \%$ of pregnancies, with the prevalence of CKD stages 1,2 , and 3 being $2.4 \%$, $0.8 \%$, and $0.1 \%$, respectively. ${ }^{1}$ Early stage CKD can be

Table I Staging of CKD (KDOQI)

\begin{tabular}{lll}
\hline Stage & Description & GFR $\left(\mathrm{mL} / \mathrm{min} / 1.73 \mathrm{~m}^{2}\right)$ \\
\hline I & $\begin{array}{l}\text { Abnormal renal morphology } \\
\text { or function with normal or }\end{array}$ & $\geq 90$ \\
increased GFR & \\
2 & $\begin{array}{l}\text { Abnormal renal morphology } \\
\text { or function with mildly }\end{array}$ & $60-89$ \\
& $\begin{array}{l}\text { decreased GFR } \\
\text { Moderate decrease in GFR }\end{array}$ & $30-59$ \\
4 & Severe decrease in GFR & $15-29$ \\
5 & End-stage renal disease & $<15$ (or dialysis dependent) \\
\hline
\end{tabular}

Notes: CKD is defined as kidney damage with alteration in morphology, imaging, or function of the kidney, or, alternatively, an eGFR of $<60 \mathrm{~mL} / \mathrm{min} / 1.73 \mathrm{~m}^{2}$ for at least 3 months. Creatinine-based equations for eGFR may be applied to preconception creatinine samples, but are not validated for pregnant women, and may underestimate or overestimate eGFR in pregnancy. Preconception CKD stage is an important determinant of obstetric and perinatal outcomes and impact of pregnancy on maternal renal health. Copyright (c) 2002 National Kidney Foundation. Reproduced with permission from NKF KDOQI Guidelines; 2002. Available from: http:// www2.kidney.org/professionals/KDOQI/guidelines_ckd/p4_class_gl.htm. Accessed October 4, 2015. ${ }^{107}$

Abbreviations: CKD, chronic kidney disease; eGFR, estimated glomerular filtration rate; KDOQI, Kidney Disease Outcomes Quality Initiative. difficult to define in pregnancy, and robust prevalence data are lacking. ${ }^{8}$ Advanced CKD (stage 3-5) is estimated to affect 1:150 women of reproductive age and 1:750 pregnancies. ${ }^{3,9}$ Population incidence rates for dialysis and transplant pregnancies vary between countries and are mostly derived from historical registry data, where there may be reporting bias especially with poor capture of early pregnancy losses. The most contemporaneous data are available from the Australian and New Zealand Dialysis and Transplant Registry (ANZDATA). The reported pregnancy rate in chronically dialyzed patients was $3.1 / 1,000$ patient-years at risk during 1966-2000 and rose to 8.4/1,000 in 2001-2011 with a live birth rate of $1.26 / 1,000$ patient-years. ${ }^{10}$ Other studies have reported a conception rate of $0.3 / 100$ patientyears in Belgium, ${ }^{11} 3.4 \%$ on hemodialysis in Japan, ${ }^{12} 2.4 \%$ on hemodialysis, and $1.1 \%$ on peritoneal dialysis in the USA. ${ }^{13}$ In ANZDATA, the pregnancy rate in female transplant recipients during 1966-2005 was 20/1,000 patient-years, with a live birth rate of $16 / 1,000$ patient-years. ${ }^{14,15}$ In the USA, the pregnancy rate in the first 3 years posttransplant between 1990 and 2003 was 33/1,000 women; the live birth rate was 19/1,000 women. ${ }^{16}$ The differences in pregnancy and live birth rates between dialyzed and transplanted women underscore the effects of CKD on fertility and markedly improved fertility and permissiveness toward pregnancy following renal transplantation.

\section{CKD stage and pregnancy outcomes}

Numerous studies exist describing pregnancy and renal outcomes in women with CKD. Importantly, interpretation and comparison of outcomes between studies is limited by small numbers, restricted clinical data, historical cohorts from different eras of medical care, heterogeneous cohorts with variable primary disease and clinical features, variable definitions of CKD, and lack of preconception GFR data. Nevertheless, it is clinically useful to broadly recognize that any maternal CKD increases the likelihood of adverse maternal-fetal outcomes, with risks compounded by advancing CKD stage, hypertension, proteinuria, and comorbidities. ${ }^{17-24}$ It is also important to note some women have uncomplicated pregnancies, and the discussion of medical risks may heighten anxiety around conception and pregnancy. ${ }^{25}$ This issue is discussed further in "Patient perspectives and shared decision making" section.

Two recent large studies by Kendrick et $\mathrm{al}^{26}$ (reporting outcomes for 778 American women with renal disease identified retrospectively by a variety of methods), and Piccoli et $\mathrm{al}^{20}$ (reporting outcomes for a prospectively recruited cohort), again highlight that CKD pregnancies 
(compared with low risk or healthy controls) have excess maternal risk of preeclampsia and cesarean section, and fetal risk of preterm birth, poor growth, low birth weight, and need for neonatal intensive care admission. The rate of pregnancy and perinatal complications (principally driven by preeclampsia) increases with worsening severity of CKD, and may occur even in women with normal eGFR without other comorbidities. ${ }^{17,20,27}$ Pregnancies in women with stage 4-5 CKD are most challenging, with hypertensive disorders and preterm birth affecting the majority. Reassuringly, while pregnancy loss is increased in women with CKD, neonatal and maternal death is rare in developed countries. ${ }^{18}$

\section{Pregnancy and progression of CKD}

The risk of renal deterioration during pregnancy remains a concern. Current evidence is conflicting. A meta-analysis by Zhang et $\mathrm{al}^{21}$ revealed no association between pregnancy and deterioration of renal function, irrespective of etiology or baseline stage, although few included studies had advanced CKD patients. Piccoli et $\mathrm{al}^{20}$ observed $7.6 \%$ of women with CKD stage 1 experienced a shift in CKD stage or start of renal replacement therapy with pregnancy, rising to $20 \%$ for women with CKD stage 4-5. Jones and Hayslett ${ }^{24}$ observed renal function in women with moderate-to-severe CKD (creatinine $>124 \mu \mathrm{mol} / \mathrm{L}$ ) during pregnancy and postpartum, reporting transient deterioration in $43 \%$ and permanent deterioration in $31 \%$ of cases. Similarly, a small but widely noted study by Imbasciati et $\mathrm{al}^{22}$ found prepregnancy eGFR $<40 \mathrm{~mL} / \mathrm{min} / 1.73 \mathrm{~m}^{2}$ with proteinuria $>1 \mathrm{~g} / 24$ hours predicted renal decline after pregnancy. Preconception graft function is similarly the key predictor of decline in kidney transplant recipients. ${ }^{28}$ Therefore, evidence that pregnancy accelerates early CKD is limited, but deterioration is more likely in women with more advanced renal disease.

\section{Primary renal diagnosis and outcomes}

CKD etiology has less influence on outcomes than CKD stage, proteinuria, hypertension, and preeclampsia. An exception is systemic lupus erythematosus (SLE) nephritis: outcomes are poorer than for women with comparable renal impairment from other causes, particularly if associated with antiphospholipid antibodies. ${ }^{29} \mathrm{~A}$ recent meta-analysis identified risks of SLE flare (25.6\%), hypertension (16.3\%), preeclampsia (7.6\%), premature birth $(39.4 \%)$, and intrauterine growth restriction $(12.7 \%)$ in 37 studies of 2,751 pregnancies. ${ }^{29}$ Differentiating preeclampsia from SLE nephritis is difficult. Key differentiating features include the typical rash, arthritis, hematuria, low complement levels in SLE, or the presence of antiphospholipid antibodies, while abnormal liver function tests suggest preeclampsia rather than SLE flare..$^{30,31}$ Overall, the prognosis for women with SLE nephritis has improved since the $1960 \mathrm{~s}$, with fetal loss rates decreasing from $40 \%$ in 1960 to $17 \%$ in $2000 .{ }^{30}$

Women with autosomal dominant polycystic kidney disease have an increased risk of preeclampsia and urinary tract infection. ${ }^{19,32}$ Hepatic cysts may enlarge in the estrogenic environment, and known cerebral aneurysms should be assessed prior to labor. ${ }^{33,34}$ There is also a risk of intracystic hemorrhage during labor, and large renal cysts should be monitored prior to and following delivery. ${ }^{35}$

Outcomes in other common nephropathies including IgA nephropathy do not consistently differ from same-stage CKD of other etiology, ${ }^{23}$ although robust comparative data between primary diseases remain limited. Diabetic patients (particularly if poorly controlled) have increased rates of preeclampsia, fetal abnormalities, and fetal loss; proteinuric diabetic nephropathy may worsen in pregnancy, and the combination of diabetes, proteinuria, renal impairment, and hypertension is particularly difficult. ${ }^{36}$ These risks may be elevated in women with "overt" diabetic nephropathy compared with those with early stage disease. ${ }^{37}$ Establishing good glycemic control and lowering the hemoglobin A1c preconception is important to improve maternal and neonatal outcomes, including reducing the risk of fetal malformation. There is some evidence that the risk of congenital abnormalities in diabetic women may be increased in the presence of nephropathy, ${ }^{38}$ underscoring the need for optimized glycemic control.

\section{Management of pregnancy in women with CKD}

An algorithm for approaching pregnancy care in women with CKD is proposed in Figure 1, and specific management points are discussed here.

\section{Preconception planning}

Given the high rate of associated morbidity, women with CKD should have prepregnancy counseling early in their disease course. Contraceptive options should be explored if a delay in pregnancy is desirable, with clear explanation of the benefits of careful pregnancy planning. Key areas for discussion include an exploration of risks and outcomes as described above, assessment of relevant risk factors; optimizing modifiable factors including control of primary renal disease and blood pressure (BP); implementation of drug changes; decisions regarding timing of conception; and development of a comprehensive pregnancy management plan. Genetic counseling should be offered to women with inheritable renal disease. As for all pregnant women, 


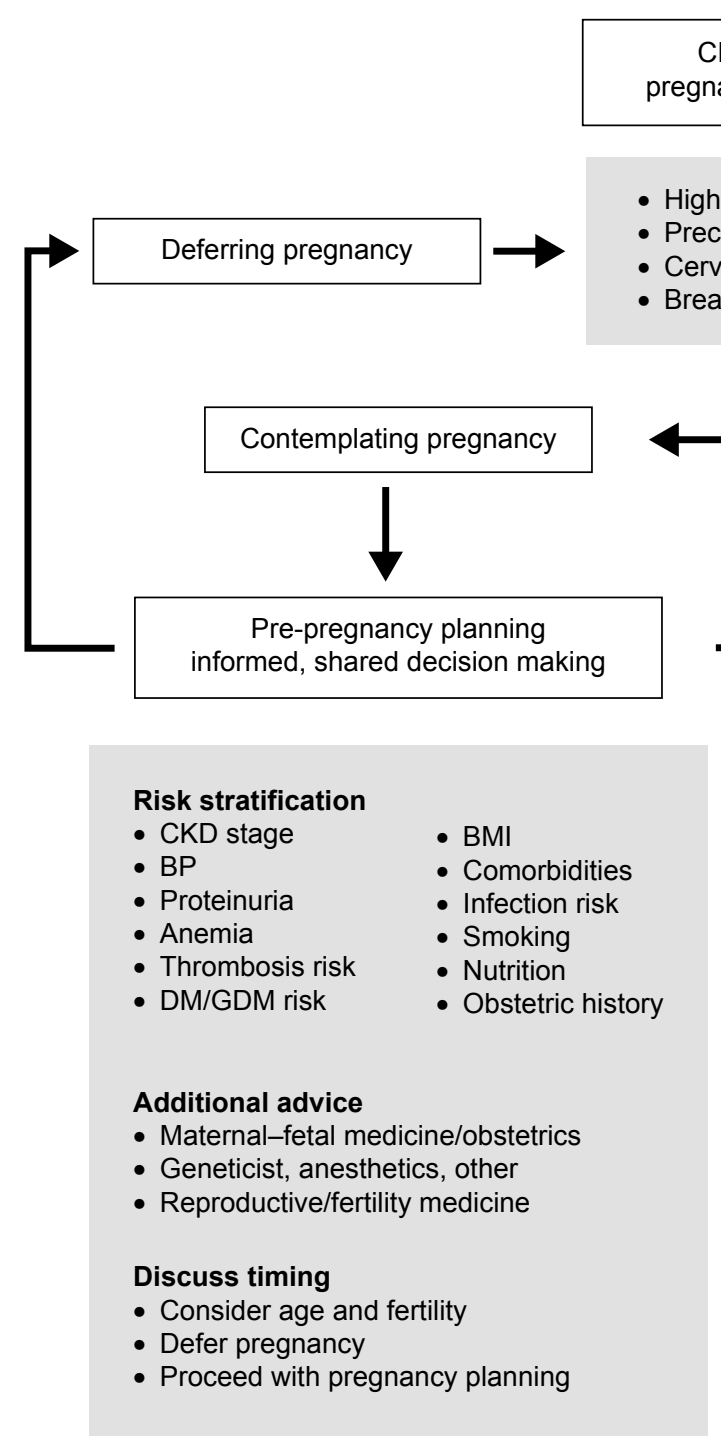

CKD with potential for

pregnancy and sexually active

- Highly effective contraception

- Precautions for STD

- Cervical cancer screening

- Breast cancer screening

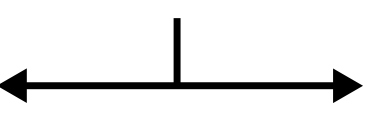

Not contemplating pregnancy

- Consider tubal ligation

Going ahead - prepare for pregnancy

Optimize maternal health

- Control of primary disease

- BP control

- Adjust medications

- Timing of ACEI/ARB cessation

- Commence folic acid

Monitor closely while trying

to conceive

to conceive

Discuss timing

- Defer pregnancy

- Proceed with pregnancy planning

Pregnancy management

- Confirm pregnancy

- Establish multidisciplinary team

- Low-dose aspirin

- Continue folic acid

Potential for pregnancy and sexually active

- Repeat algorithm

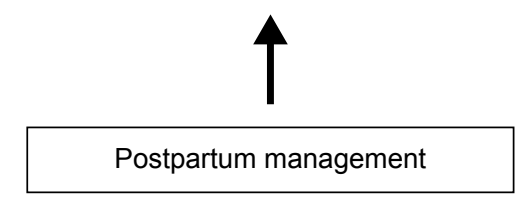

- Breastfeeding

- Monitor and manage renal disease

- Adjust medications

- Contraception

- Plan delivery

\section{Maternal surveillance}

- Renal function - monthly*

- Proteinuria - monthly*

- Blood pressure - weekly*

- Bacteriuria - each trimester*

- GDM screening - possibly early

- Immunosuppression levels - monthly*

- Immune parameters (eg, in SLE)

Fetal surveillance

- First and second trimester screening

- Growth scans after 28-30 weeks

- Doppler studies

- Cardiotocographs

- Cardiac monitoring in Ro+/La+ women

Figure I Algorithm for pregnancy care in women with CKD.

Note: *Or more frequently if required.

Abbreviations: ACEI, angiotensin-converting enzyme inhibitor; ARB, angiotensin receptor blocker; BMI, body mass index; BP, blood pressure; CKD, chronic kidney disease; DM, diabetes mellitus; GDM, gestational diabetes mellitus; SLE, systemic lupus erythematosus; STD, sexually transmitted disease. 
preconception and first trimester folic acid supplementation is recommended. In dialyzed women, $3-5 \mathrm{mg}$ /day may be required, due to losses during dialysis.

Pregnant women with CKD benefit from specialized (tertiary or quaternary) multidisciplinary team management including obstetricians, obstetric physicians/nephrologists, anesthetists, dietetic, and midwifery input. ${ }^{39,40}$ While the overall risk of pregnancy problems is increased in women with CKD, many women will have uncomplicated pregnancies and excellent outcomes, but still require frequent antenatal review, particularly monitoring maternal renal function and $\mathrm{BP}$, and fetal growth and well-being.

\section{Management of primary disease}

Women with glomerulonephritis including lupus nephritis require quiescent disease and stable immunosuppression for at least 6 months prior to conception. Immunosuppression should be adjusted and continued throughout pregnancy to abrogate risk of disease flare (Table 2), with recent reports of successful use of tacrolimus for SLE nephritis in pregnancy. ${ }^{41}$ Women with SLE should have testing for anti-Ro and anti-La antibodies, which are associated with neonatal lupus and congenital heart block, and markers of antiphospholipid antibody syndrome, which may necessitate specific management in pregnancy. ${ }^{29,31}$ Hydroxychloroquine should be continued through pregnancy in Ro+/La+ women. Stanhope et $\mathrm{al}^{31}$ provide an excellent algorithm for the management of lupus nephritis in pregnancy.
Comorbid conditions require specific attention. Good diabetic control is important preconception and during pregnancy, and is associated with better outcomes. ${ }^{36}$ Urine surveillance should occur regularly, with aggressive treatment of asymptomatic bacteriuria, particularly in women with reflux nephropathy, autosomal dominant polycystic kidney disease, and immunosuppression. Prophylactic antibiotics should be considered for the remainder of the pregnancy after a first episode of urinary tract infection, although this is not universally implemented. ${ }^{3,42}$

\section{Diagnosis of pregnancy}

Renal excretion of $\beta$-human chorionic gonadotropin ( $\beta$-hCG) produced by somatic cells is reduced in CKD. Urine pregnancy tests may be falsely positive. Serial blood $\beta-\mathrm{hCG}$ testing and pelvic ultrasound are useful to confirm pregnancy and determine accurate gestational age, rather than date of last menstrual cycle, as irregular cycles and anovulation are common in advanced CKD.

\section{Antenatal screening}

Women with CKD should be offered standard antenatal screening as per local practice, but interpreted cautiously. First trimester screening for aneuploidies involves ultrasound nuchal translucency measurement and serum-free $\beta-\mathrm{hCG}$ and pregnancy-associated plasma protein A (PAPP-A). ${ }^{43,44}$ In the second trimester, free $\beta$-hCG, unconjugated estradiol, $\alpha$-fetoprotein, and inhibin A is measured. Impaired renal

Table 2 Recommendations for immunosuppressant medications in pregnancy

\begin{tabular}{|c|c|c|}
\hline Drug & Pregnancy effects & Recommendation in pregnancy \\
\hline \multirow[t]{2}{*}{ Prednisolone } & Maternal hypertension and GDM & May be continued \\
\hline & $\begin{array}{l}\text { Risk of thymal hyperplasia and adrenal suppression in neonate } \\
\text { with high doses }\end{array}$ & Avoid prolonged high doses \\
\hline \multirow[t]{2}{*}{ Azathioprine } & No teratogenicity & May be continued \\
\hline & Unable to be activated by fetal liver & \\
\hline \multirow[t]{5}{*}{ Tacrolimus } & Potential increased risk of GDM & May be continued \\
\hline & Risk of transient neonatal renal dysfunction and hyperkalemia & Monitor and adjust levels \\
\hline & & Early OGTT in pregnancy especially \\
\hline & & if combined with prednisolone \\
\hline & & Check neonatal biochemistry \\
\hline \multirow[t]{3}{*}{ Cyclosporine A } & No teratogenicity & May be continued \\
\hline & Associated with maternal hypertension & Monitor and adjust levels \\
\hline & Reversible effect on fetal lymphocytes & \\
\hline \multirow[t]{3}{*}{ Mycophenolate mofetil } & Teratogenic and embryopathic & Cease 12 weeks prior to conception \\
\hline & Multiple congenital defects of ears, digits, oral cavity & \\
\hline & Increased pregnancy loss & \\
\hline \multirow[t]{2}{*}{ Cyclophosphamide } & Teratogenic in first trimester & Cease 12 weeks preconception \\
\hline & Affects ovarian function and fertility & Use in later pregnancy if critical to maternal life \\
\hline Sirolimus & Animal studies suggest teratogenicity, effects on bone and fetal & Cease 12 weeks preconception due to lack \\
\hline Everolimus & growth. Data remain very limited & of data to support safe use \\
\hline (mTOR inhibitors) & & \\
\hline
\end{tabular}

Note: Data from Bramham et al, ${ }^{39}$ KDIGO, ${ }^{80}$ McKay et al, ${ }^{86}$ Hebert et al,,${ }^{93}$ Thiagarajan et al, ${ }^{99}$ Sifontis et al, ${ }^{108}$ and Tendron et al ${ }^{109}$.

Abbreviations: GDM, gestational diabetes mellitus; mTOR, mammalian targets of rapamycin; OGTT, oral glucose tolerance test. 
clearance of free $\beta$-hCG may affect test validity. Benachi et a ${ }^{45}$ investigated free and total $\beta-\mathrm{hCG}$ in the second trimester to determine those "at risk" of Down syndrome (defined as risk of $>1: 250$ ). A significantly higher number of women with CKD met "at risk" criteria using free $\beta$-hCG ( $48 \%$ vs $12 \%$ of controls), whereas total hCG gave a nonsignificant difference ( $25 \%$ vs $15 \%$ ). Levels of $\alpha$-fetoprotein, utilized in screening for neural tube defects, are not affected by renal disease $.^{46} \mathrm{PAPP}-\mathrm{A}$ is a risk marker for small-for-gestationalage (SGA) babies. PAPP-A has been studied as a biomarker in CKD generally. While still interpretable in early stage CKD in pregnancy, PAPP-A is unreliable in late CKD including dialysis ${ }^{47}$ and falsely elevated in women receiving heparin. ${ }^{48}$ Unconjugated estriol is cleared by dialysis, unlike $\alpha$-fetoprotein and $\beta$-hCG. ${ }^{46}$ No data exist regarding noninvasive renal testing using cell-free placental DNA in CKD cohorts. Further studies are required to improve interpretation of screening tests in CKD patients.

\section{Hypertension}

Controlling hypertension before and during pregnancy is essential. A meta-analysis by Bramham et $\mathrm{al}^{49}$ of nearly 800,000 pregnancies in non-CKD chronic hypertensive women demonstrated markedly increased risks of superimposed preeclampsia, cesarean section, preterm delivery, intensive care admission, and perinatal death. Hypertension is an additive risk factor at all stages of CKD. Piccoli et $\mathrm{al}^{20}$ reported threefold higher odds for preterm birth in hypertensive women versus normotensive women with stage $1 \mathrm{CKD} .{ }^{20}$ A similar additive effect was reported by Munkhaugen et al, ${ }^{1}$ with a combined odds of preeclampsia, preterm birth, or SGA of 1.18 versus 4.24 in normotensive women versus hypertensive women with eGFR $<90 \mathrm{~mL} / \mathrm{min} / 1.73 \mathrm{~m}^{2}$ compared to those with higher eGFR.

There is insufficient evidence regarding BP targets and treatment-related modification of outcomes in hypertensive CKD pregnancies, ${ }^{50}$ although the National Institute for Health and Care Excellence guidelines recommend maintaining BP $<140 / 90 \mathrm{mmHg}$ in hypertensive women with CKD. Concerns regarding effects of lower BP on fetal growth ${ }^{51}$ were addressed in the CHIPS trial, where tighter control of diastolic BP reduced severe maternal hypertension with no significant fetal impact. ${ }^{52}$ However, caution should be used in extrapolating these findings to women with CKD owing to potential differences in vascular disease burden or placentation.

First-line medications commonly used for pregnancy hypertension include methyldopa, labetalol, and nifedipine.
Antihypertensive management in pregnancy has been recently comprehensively summarized in international guidelines. ${ }^{53-55}$

Angiotensin-converting enzyme (ACE) inhibitors and angiotensin receptor blockers are contraindicated due to intrauterine growth restriction, renal dysplasia, oligohydramnios, and fetal death. ${ }^{56}$ Cooper et al ${ }^{56}$ suggested a $>$ twofold increased risk of congenital malformations associated with first trimester usage, notably cardiac and central nervous system abnormalities, but could not adjust for the confounder of maternal diabetes. More recent studies suggest that congenital defects are related to hypertension and comorbidities, not ACE inhibitors themselves. ${ }^{49,57}$ Given the anti-proteinuric benefits of renin-angiotensin-aldosterone system blockade, continuing these drugs until conception is confirmed may be considered acceptable in proteinuric patients. ${ }^{58}$

\section{Preeclampsia prophylaxis and diagnosis}

Studies of aspirin for preeclampsia risk reduction in the CKD pregnant cohort are limited, and management recommendations are extrapolated from studies in low-risk cohorts. The National Institute for Health and Care Excellence guidelines currently support low-dose aspirin ( $75 \mathrm{mg}$ /day) for women with CKD from 12 weeks until delivery. ${ }^{59} \mathrm{~A}$ Cochrane review of aspirin for preeclampsia prevention identified a significant $5.2 \%$ decrease in the absolute risk of preeclampsia among high-risk women in 59 trials. ${ }^{60}$ Therefore, aspirin is recommended in women with hypertension and CKD, particularly women with SLE. ${ }^{30}$

Diagnosing preeclampsia in women with CKD presents a specific diagnostic challenge. The clinical features of worsening hypertension, proteinuria, or biochemical parameters may be a manifestation of underlying renal disease affected by pregnancy, or may represent preeclampsia. Nonrenal parameters such as liver enzymes and platelet count are most useful. Renal biopsy is rarely indicated. Preliminary studies suggest assays of soluble fms-like tyrosine kinase (sFLT-1), placental growth factor, and serum placental protein 13 may assist in differentiating preeclampsia from CKD, and predicting preeclampsia in high-risk populations, including women with CKD. ${ }^{61,62}$ Although not widely available, these biomarkers are being validated in CKD patients and may significantly influence future management. ${ }^{63}$

Management, including timing of delivery, for women with CKD and superimposed preeclampsia should be according to local practices for non-CKD preeclampsia, with focus on controlling $\mathrm{BP}$ and monitoring renal function peripartum and on an ongoing basis postpartum. 


\section{Proteinuria and nephrotic syndrome}

Proteinuria is an important parameter for risk stratification of maternal CKD. The sensitivity and specificity of the spot protein/creatinine ratio is adequate to exclude significant proteinuria, and enable monitoring of existing proteinuria. However, in many centers, 24-hour urine collections remain the preferred test. Proteinuria is more likely to commence or worsen in pregnancy as CKD stage advances, and is probably independently associated with adverse pregnancy outcome. ${ }^{17,20}$ In women with diagnosed pregnancy hypertension or preeclampsia, the severity of proteinuria has not been shown to consistently predict maternal or fetal outcomes. ${ }^{64}$

Little data are available regarding prophylaxis against venous thromboembolism in women who develop nephroticrange proteinuria or nephrotic syndrome in pregnancy. Given the prothrombotic risks of nephrotic syndrome and pregnancy, along with other risk factors including obesity and immobility, it may be appropriate to commence prophylaxis with low-molecular-weight heparin. Doses should be corrected for renal function in advanced CKD. If underlying glomerulonephritis is suspected, immunosuppression may be appropriate. Substantial edema may be managed with diuretics, with monitoring for oligohydramnios. Albumin infusion has also been used; however, the supporting evidence is insufficient and proteinuria may be paradoxically increased. ${ }^{58}$

\section{Pregnancy in dialyzed women}

Despite reduced fertility in women with advanced (stage 4-5) CKD undergoing dialysis, pregnancies still occur, presenting significant clinical challenges. Historically, high rates of fetal loss $(>50 \%)$ and generally poor outcomes reinforced clinical pessimism. However, since the late 1990s, with recognition that increased dialysis intensity improves outcomes, successful birth rates have risen to $70 \%-90 \%$, although pregnancies remained complicated by hypertension $(50 \%-70 \%)$, preeclampsia (18\%-67\%), polyhydramnios (up to $40 \%$ ), intrauterine growth restriction $(17 \%-77 \%)$, and prematurity and low birth weight $(50 \%-100 \%){ }^{8,10,13,22,65-67}$ Saliem et al ${ }^{66}$ compared obstetric outcomes in dialyzed women with transplanted women, and found that many complications including hypertensive disorders and preterm birth occurred with equal frequency; however, dialyzed mothers were more likely to have growth-restricted babies, placental abruption, blood transfusions, and intrauterine fetal death.

Improvements in live birth, gestational age, and birth weight have been observed with intensive hemodialysis regimens, achieved via daily (or near-daily) treatments, longer treatment hours, or nocturnal dialysis. ${ }^{65,68-73}$ Piccoli et $\mathrm{al}^{74}$ recently demonstrated a relationship between greater number of hours of dialysis and the reduced risk of preterm delivery or SGA neonate in a metaregression. Intensive hemodialysis is now the standard model of care for women receiving dialysis in pregnancy, particularly if residual renal function is minimal. The Italian Study Group of the Kidney and Pregnancy suggests daily nocturnal dialysis for women without residual renal clearance, aiming for at least 36 hours per week. ${ }^{68}$ Hladunewich et a ${ }^{69}$ have recently demonstrated substantially improved outcomes in 22 Canadian women treated with intensive dialysis compared with an American registry cohort. Long-hours dialysis achieves lower maternal urea levels, reducing fetal-osmotic diuresis and polyhydramnios, and avoiding rapid fluid shifts, uteroplacental hypoperfusion, and fetal distress. Treatment should aim for predialysis blood urea nitrogen levels $<50 \mathrm{mg} / \mathrm{dL}$ $(17.9 \mathrm{mmol} / \mathrm{L})$ or urea levels $<100 \mathrm{mg} / \mathrm{dL}(16.6 \mathrm{mmol} / \mathrm{L})$; women with residual renal function may require less intense dialysis to achieve these targets. ${ }^{68-70}$ Hemodialysis management considerations include attention to predialysis biochemical parameters, frequent review of ideal weight, BP control, anticoagulation, diet modifications, and anemia management. Detailed management is beyond the scope of this review, and recent expert recommendations have been published. ${ }^{68,70}$

Data regarding pregnancy outcomes in women receiving peritoneal dialysis are limited to individual case reports, an Australian series of five patients, ${ }^{75}$ and minimal representation in registry data. ANZDATA registry data suggest lower conception rates in women receiving peritoneal dialysis, ${ }^{10,14}$ possibly due to hypertonic fluid and adhesions disturbing implantation. ${ }^{42}$ The dialysis prescription may require adjustment to limit abdominal fullness, with more frequent exchanges and smaller volumes, and vigilance for peritonitis. Evidence favoring initiation of peritoneal dialysis over hemodialysis in advanced CKD pregnancies is limited. In the ANZDATA cohort, most women switched from peritoneal dialysis to hemodialysis in pregnancy. ${ }^{10}$ In maintenance dialysis patients, continuing an intensified version of the established dialysis is reasonable in pregnancy, providing that good dialysis efficiency is achieved. ${ }^{68}$

\section{Timing of conception in dialyzed women}

The timing of initiating dialysis has prognostic significance because residual renal function is an important determinant of outcome. ${ }^{10,65}$ Data from the ANZDATA registry demonstrated superior live birth rates ( $91 \%$ vs $63 \%)$, but no difference in 
gestational age or birth weight, in women with advanced CKD who commence chronic dialysis (predominantly hemodialysis) during pregnancy, compared with women already receiving chronic dialysis at conception. ${ }^{10}$ Those women commencing dialysis after conception had higher eGFR at dialysis initiation than the chronic cohort. While there is no evidence regarding the optimal time to initiate dialysis in women with advanced CKD in pregnancy, most clinicians would consider a lower threshold than in the nonpregnant patient, usually once serum urea is $>20 \mathrm{mmol} / \mathrm{L}$.

\section{Pregnancy in transplant recipients}

Fertility is significantly increased after kidney transplantation, and the chances of successful birth are markedly increased compared with the dialysis cohort. ${ }^{67}$ The ANZDATA registry has reported an overall live birth rate of $76 \%$ (97.8\% for pregnancies reaching $>20$ weeks gestation), with most pregnancy losses occurring in the first trimester, and the rate of elective termination falling over time from $25 \%$ in the $1970 \mathrm{~s}$ to $3 \%$ in the 2000 s. $^{15,76,77}$ Although rare, successful pregnancies utilizing assisted reproduction technology including in vitro fertilization have also been reported for the transplant cohort. ${ }^{76,78}$ The results of these studies should be interpreted with caution, as there may be selection bias, and there may be risks of hormonal conditioning in transplant patients.

The American Society of Transplantation first published guidelines for the management of kidney transplant pregnancies in 2005, ${ }^{79}$ with further recommendations by the National Kidney Foundation KDIGO group in 2009. ${ }^{80}$ Since that time, there has been an explosion of data with numerous registry and cohort studies, systematic reviews, and a meta-analysis reporting kidney transplant pregnancy outcomes. ${ }^{16,66,67,76-78,81-87}$ The universal finding is that even in successfully transplanted women, substantial rates of important obstetric complications are observed. In particular, preeclampsia occurs in $25 \%-35 \%$ of pregnancies, and growth restriction or preterm birth in $30 \%-50 \%$; rates have been shown to be similar between transplanted and dialyzed women. ${ }^{66}$ The ANZDATA registry analyses demonstrated a difference in mean gestational age of 3.5 weeks and birth weight of $873 \mathrm{~g}$ for babies of transplanted women compared with the Australian birth cohort, a difference that has clinical relevance for those babies. ${ }^{76}$ Women who are transplanted as children have similar pregnancy outcomes compared with women transplanted as adults, despite longer exposure to kidney failure and immunosuppression. ${ }^{77}$

For women with stable and good allograft function, pregnancy does not appear to adversely impact long-term graft function or patient survival, although some women will have transient graft dysfunction or failure of creatinine to fall during pregnancy. ${ }^{15,28,84,85}$ Surprisingly low rates of acute rejection have been reported during pregnancy, $<6 \%$ in most studies ${ }^{83,84}$ In addition, the risk of de novo allosensitization after pregnancy in a transplanted women is also $<6 \%{ }^{88}$ Risk factors for inferior perinatal outcomes and decline in maternal graft function are likely similar to those observed in CKD cohorts, with preconception graft function shown to be a key determinant. ${ }^{84,87}$ More data are required regarding long-term graft and infant outcomes and methods of risk stratification. Of particular concern are those women with borderline preconception allograft function; the long-term impact of pregnancy is much less defined in this cohort.

Clinical management is largely similar to the CKD pregnancy cohort. Issues specific to transplanted women include determining appropriate timing of conception posttransplant, adjustment of immunosuppression, surveillance of allograft function, and vigilant monitoring for preeclampsia, rejection, and infection in the immunocompromised recipient (Figure 1). As in women with CKD, distinguishing preeclampsia from chronic hypertension or graft rejection can present a diagnostic dilemma.

The optimal timing of pregnancy is not conclusively established by the available data, but must be balanced against the window of opportunity for childbearing. Effective contraception should be strongly recommended peritransplantation; ${ }^{80}$ contraceptive options require careful consideration based on comorbidities and individual factors, however, intrauterine devices or combined barrier/hormonal methods are considered the safest option. ${ }^{89,90}$ Pregnancy occurring within 1 year from transplantation may be safe, ${ }^{91}$ but other studies suggest a longer time posttransplant is favorable. ${ }^{16,76}$ The recommended interval of transplantation to pregnancy is $1-2$ years, provided graft function is stable, hypertension controlled, and the immunological environment favorable with low risk of rejection or infection. ${ }^{83,89,90}$ Reported average transplant pregnancy intervals in Australia and New Zealand are in fact much longer (3-5 years). ${ }^{76}$ Infections such as cytomegalovirus are much less common by this time, but status should be checked prepregnancy.

Immunosuppressive therapy must be adjusted preconception in transplant and nontransplant patients. Table 2 summarizes general recommendations. Graft function should be monitored for at least 3 months following immunosuppression changes, with reassessment of donor-specific antibodies in sensitized recipients. Most studies report a large number of immunosuppression combinations used in pregnancy, making 
subanalysis of immunosuppression and pregnancy outcomes difficult. Calcineurin inhibitors (tacrolimus or cyclosporine), prednis(ol)one, and azathioprine are most commonly used, and considered reasonably safe, without increased risk of congenital defects above the background population rate. ${ }^{83,89,92}$ During pregnancy, blood levels of tacrolimus and cyclosporine may fall, necessitating surveillance and dose adjustment. ${ }^{92}$ Tacrolimus pharmacokinetics alter in pregnancy with increased unbound active fraction, although this is not routinely measured..$^{93}$ Tacrolimus and prednis(ol)one have been associated with diabetes mellitus, but evidence for increased rates of gestational diabetes in the kidney transplant cohort is inconclusive. ${ }^{15,84,85}$ Mycophenolate mofetil is known to increase early pregnancy loss and birth defects, and should be ceased preconception..$^{94}$ More data are needed to explore the safety of mammalian targets of rapamycin inhibitors in pregnancy, with some evidence of effect on fetal metabolism and growth; ${ }^{95}$ therefore, avoidance is preferable.

\section{Fetal monitoring}

Decisions regarding the timing of delivery depend on maternal and fetal well-being, balanced against the gestational age. Fetal surveillance should be conducted by experienced sonographers ideally with materno-fetal medicine obstetricians. Ultrasound assessment of fetal growth, amniotic fluid volume, and Doppler assessment of uterine, umbilical, and fetal cerebral vessels, and ductus venosus provide important information regarding fetal well-being, and should be performed fortnightly from 28 to 30 weeks. The value of each parameter alters depending on gestational age. ${ }^{96}$ Changes in the umbilical artery such as absent flow or reversed end-diastolic flow reflect increased placental vascular resistance and precede alterations in middle cerebral artery blood flow and brain sparing, which reflect late fetal compromise. ${ }^{96,97}$ Polyhydramnios is common in the setting of maternal diabetes or high serum urea. Cardiotocography may be used after 28 weeks to assess fetal condition, especially in women receiving dialysis. Surveillance for intrauterine growth restriction or other fetal compromise is imperative as this is often the primary precipitant for early delivery.

\section{Timing and type of delivery}

No data are available in the CKD population regarding optimal timing; however, rapidly worsening maternal or fetal parameters usually warrant delivery. Local practices for women with chronic hypertension or preeclampsia should be followed. The HYPITAT-II trial regarding induction of labor versus expectant management for women with nonsevere hypertensive disorders between 34 and 37 weeks did not support routine immediate delivery, as the nonsignificant reduction in maternal complications was outweighed by the significantly elevated risk of neonatal respiratory distress. ${ }^{98}$ Delivery should be conducted as per usual local practice. There is no specific indication for cesarean section in women with renal impairment, including women with transplants, although cesarean section rates are significantly higher in renal cohorts, likely driven by emergency deliveries. ${ }^{19,20}$ The location of the transplant, ureter, and vessels should be reviewed with the obstetric team, in liaison with the transplant surgical team, if required.

\section{Breastfeeding}

The benefits of breastfeeding (particularly for preterm infants) may outweigh theoretical risks of adverse effects on infants; therefore, breastfeeding options should be considered well before delivery. All hypertensive medications used antenatally are suitable for breastfeeding, in addition to enalapril, captopril, and quinapril. ${ }^{53}$ Data remain limited for many immunosuppressants, but breast milk exposure is likely minimal. ${ }^{99}$ Glucocorticoids and azathioprine are relatively safe. Recent data regarding tacrolimus and cyclosporine suggest minimal fetal exposure via breast milk, and as such patients should not be discouraged from breastfeeding. ${ }^{93,99-101}$ Breastfeeding cannot be safely recommended while taking mycophenolate or mammalian targets of rapamycin inhibitors due to lack of data. It should be noted that current counseling practices differ between centers.

\section{Contraceptive counseling}

Given the increased morbidity of unplanned pregnancy where medical issues are not optimized, contraceptive counseling is essential at all CKD stages, even where fertility may be severely reduced by CKD or age. ${ }^{39}$ Contraceptive choices must be individualized by comorbidity, and potentially serious side effects balanced against risks of pregnancy. Contraceptive options for women with CKD broadly involve barrier methods, hormonal methods, and intrauterine devices; however, there are little data on efficacy and failure rates in women with kidney disease..$^{90,102,103}$ Barrier methods alone are insufficient to deliver the highly effective contraception required in this cohort. Surgical sterilization should be considered if the family is completed. The UK Royal College of Obstetricians and Gynaecologists provides an excellent guide for contraceptive risk-benefit decision making in women with hypertension and other comorbidities, although not specifically renal disease (Table 3 ). ${ }^{104}$ 
Table 3 Summary of RCOG guidance on contraceptive use in hypertension, diabetes, and SLE ${ }^{104}$

\begin{tabular}{|c|c|c|c|}
\hline $\begin{array}{l}\text { Contraceptive } \\
\text { method }\end{array}$ & Hypertension & Diabetes & SLE \\
\hline Combined OCP & $\begin{array}{l}\text { Risks outweigh benefits even in controlled } \\
\text { hypertension } \\
\text { Unacceptable risk if BP }>160 / 100 \mathrm{mmHg} \\
\text { or vascular disease present }\end{array}$ & $\begin{array}{l}\text { Benefit outweighs risk in uncomplicated } \\
\text { diabetes } \\
\text { Risks outweigh benefits in diabetic } \\
\text { nephropathy, retinopathy, or vascular } \\
\text { disease }\end{array}$ & $\begin{array}{l}\text { Benefit outweighs risk in } \\
\text { uncomplicated disease } \\
\text { Unacceptable to use in APLAS }\end{array}$ \\
\hline Progesterone-only OCP & $\begin{array}{l}\text { Acceptable to use } \\
\text { Benefits outweigh risks if vascular disease } \\
\text { present }\end{array}$ & Benefits outweigh risks & $\begin{array}{l}\text { Benefit outweighs risk in } \\
\text { uncomplicated SLE and APLAS }\end{array}$ \\
\hline Subdermal implants & $\begin{array}{l}\text { Acceptable to use } \\
\text { Benefits outweigh risks if vascular disease } \\
\text { present }\end{array}$ & Benefits outweigh risks & $\begin{array}{l}\text { Benefit outweighs risk in } \\
\text { uncomplicated SLE and APLAS }\end{array}$ \\
\hline $\begin{array}{l}\text { Injectable } \\
\text { medroxyprogesterone }\end{array}$ & $\begin{array}{l}\text { Acceptable to use if } B P<160 / 100 \text {. } \\
\text { Benefits outweigh risks at other levels } \\
\text { of BP. Risks outweigh benefits if vascular } \\
\text { disease present. }\end{array}$ & $\begin{array}{l}\text { Benefit outweighs risk in uncomplicated } \\
\text { diabetes }\end{array}$ & $\begin{array}{l}\text { Benefit outweighs risk in } \\
\text { uncomplicated SLE and APLAS }\end{array}$ \\
\hline $\begin{array}{l}\text { Levonorgestrel } \\
\text { intrauterine device }\end{array}$ & $\begin{array}{l}\text { Acceptable to use in controlled } \\
\text { hypertension } \\
\text { Benefits may outweigh risks in those } \\
\text { with vascular disease }\end{array}$ & Benefits outweigh risks & $\begin{array}{l}\text { Benefit outweighs risk in } \\
\text { uncomplicated SLE and APLAS }\end{array}$ \\
\hline Copper IUD & Acceptable to use & Acceptable to use & Acceptable to use \\
\hline \multicolumn{4}{|c|}{$\begin{array}{l}\text { Notes: No guidelines are available for CKD apart from diabetic nephropathy. "Acceptable to use" and "benefits outweigh risks" indicate an option that can be used. "Risks } \\
\text { outweigh benefits" indicate this option should be used with caution under specialist guidance and only if other methods are not available. (Copyright } \odot 2016) \text {. Adapted } \\
\text { from Faculty of Sexual and Reproductive Healthcare, Royal College of Obstetricians and Gynaecologists [Internet]. UK Medical Eligibility Criteria for Contraceptive Use; } \\
\text { https://www.fsrh.org/documents/ukmec-2016/. }{ }^{104}\end{array}$} \\
\hline
\end{tabular}

Oral contraceptive pills (OCPs) containing estrogen are generally contraindicated in women with cardiovascular disease, a history of thromboembolism, and smokers $>35$ years of age, and relatively contraindicated in hypertension, diabetes mellitus, or SLE. ${ }^{102}$ A low-dose OCP is preferred. However, given the availability of safer alternatives, other contraceptive methods are more appropriate in women with hypertension.

Progesterone-only contraceptives may be an effective and safer option, including the progesterone-only OCP, subdermal implants or intrauterine devices, and injectable medroxyprogesterone (Table 3). Among the choices for progesterone-only OCPs, desogestrel-containing pills have the advantage of a longer window of action. Potential benefits of progesteroneonly contraceptives include amenorrhea, which may assist with the management of iron deficiency anemia..$^{90}$ Nonhormonal (copper) intrauterine devices overcome some limitations of hormonal methods, although some have had concerns regarding efficacy in immunosuppressed women. ${ }^{102}$

Emergency contraception is likely safe in this cohort. Medical abortion with mifepristone or misoprostol has been reported in women with $\mathrm{CKD}$, without complications, but should be used cautiously due to lack of data. ${ }^{105}$

\section{Patient perspectives and shared decision making}

Few studies have examined patients' perspectives of pregnancy and CKD, which is of importance in guiding clinical approaches to preconception counseling. Our group undertook a systematic review and thematic synthesis of 15 qualitative studies including 257 women with renal disease, identifying themes including a strong desire for fulfilling motherhood, guilt at failure to meet societal expectations, fear of birth defects and fetal harm, emotional conflict in decision making, fears of exacerbating disease, and issues around control and determination. ${ }^{106}$ Our subsequent study explored pregnancy experiences in 41 Australian women from two centers with CKD stages $3 b-5^{25}$ and highlighted the complexities of navigating parenthood with CKD. Major themes identified included a sense of physical failure and fragility due to $\mathrm{CKD}$, feelings of loss when denied motherhood, guilt in relation to disappointing partners and family, guilt at gambling with their health, and rationalizing the health risks of pregnancy in order to pursue motherhood. Women who chose to prioritize survival described strategies for coping with loss of motherhood by reorienting focus toward positive elements of their lives. A key concern was distress at clinician focus on 
negative outcomes, perceived discouragement and judgment by medical professionals, and a lack of ownership in the decision-making process. Significant hope was provided by a positive attitude from clinicians. A recent cross-sectional analysis of the perspectives of 179 British women with CKD receiving counseling within a multidisciplinary renal-focused obstetric clinic found that preconception counseling aided decision making for $92 \%$ of participants, with only $17 \%$ intimidated by the process. ${ }^{40}$ The findings highlighted the crucial value of preconception counseling to women with CKD and their partners for shared decision making with clinicians, in a way that acknowledges the women's goals and priorities, and is adapted to the differing needs of this high-risk cohort.

\section{Conclusion}

Maternal CKD in pregnancy presents a number of challenges to women and clinicians, even at early stages of disease, with escalating obstetric and perinatal risks according to disease stage and comorbidity. Preconception counseling is essential to support women in making informed, autonomous decisions, and to maximize opportunities to modify medical care to optimize outcomes if pregnancy occurs. A multidisciplinary specialized team approach is integral to the care of these women and their babies.

\section{Acknowledgment}

The authors thank Dr Kevin Chen for his contribution to the literature review.

\section{Disclosure}

The authors report no conflicts of interest in this work.

\section{References}

1. Munkhaugen J, Lydersen S, Romundstad PR, Wideroe TE, Vikse BE, Hallan S. Kidney function and future risk for adverse pregnancy outcomes: a population-based study from HUNT II, Norway. Nephrol Dial Transplant. 2009;24:3744-3750.

2. Odutayo A, Hladunewich M. Obstetric nephrology: renal hemodynamic and metabolic physiology in normal pregnancy. CJASN. 2012;7: 2073-2080.

3. Williams D, Davison J. Chronic kidney disease in pregnancy. BMJ. 2008; 336:211-215.

4. Cote AM, Brown MA, Lam E, et al. Diagnostic accuracy of urinary spot protein:creatinine ratio for proteinuria in hypertensive pregnant women: systematic review. BMJ. 2008;336:1003-1006.

5. Alper AB, Yi Y, Webber LS, et al. Estimation of glomerular filtration rate in preeclamptic patients. Am J Perinatol. 2007;24:569-574.

6. Koetje PM, Spaan JJ, Kooman JP, Spaanderman ME, Peeters LL. Pregnancy reduces the accuracy of the estimated glomerular filtration rate based on Cockroft-Gault and MDRD formulas. Reprod Sci. 2011;18: 456-462.

7. Piccoli GB, Daidola G, Attini R, et al. Kidney biopsy in pregnancy: evidence for counselling? A systematic narrative review. BJOG. 2013;120: $412-427$.
8. Piccoli GB, Conijn A, Consiglio V, et al. Pregnancy in dialysis patients: is the evidence strong enough to lead us to change our counseling policy? CJASN. 2010;5:62-71.

9. Coresh J, Selvin E, Stevens LA, et al. Prevalence of chronic kidney disease in the United States. JAMA. 2007;298:2038-2047.

10. Jesudason S, Grace BS, McDonald SP. Pregnancy outcomes according to dialysis commencing before or after conception in women with ESRD. CJASN. 2014;9:143-149.

11. Bagon JA, Vernaeve H, De Muylder X, Lafontaine, JJ, Martens, J, Van Roost G. Pregnancy and dialysis. Am J Kidney Dis. 1998;31:756-765.

12. Toma H, Tanabe K, Tokumoto T, Kobayashi C, Yagisawa T. Pregnancy in women receiving renal dialysis or transplantation in Japan: a nationwide survey. Nephrol Dial Transplant. 1999;14:1511-1516.

13. Okundaye I, Abrinko P, Hou S. Registry of pregnancy in dialysis patients. Am J Kidney Dis. 1998;31:766-773.

14. Shahir AK, Briggs N, Katsoulis J, Levidiotis V. An observational outcomes study from 1966-2008, examining pregnancy and neonatal outcomes from dialysed women using data from the ANZDATA Registry. Nephrology. 2013;18:276-284.

15. Levidiotis V, Chang S, McDonald S. Pregnancy and maternal outcomes among kidney transplant recipients. JASN. 2009;20:2433-2440.

16. Gill JS, Zalunardo N, Rose C, Tonelli M. The pregnancy rate and live birth rate in kidney transplant recipients. Am J Transplant. 2009;9: 1541-1549.

17. Bramham K, Briley AL, Seed PT, Poston L, Shennan AH, Chappell LC. Pregnancy outcome in women with chronic kidney disease: a prospective cohort study. Reprod Sci. 2011;18:623-630.

18. Kendrick J, Sharma S, Holmen J, Palit S, Nuccio E, Chonchol M. Kidney disease and maternal and fetal outcomes in pregnancy. Am J Kidney Dis. 2015;66:55-59.

19. Nevis IF, Reitsma A, Dominic A, et al. Pregnancy outcomes in women with chronic kidney disease: a systematic review. CJASN. 2011;6: 2587-2598.

20. Piccoli GB, Cabiddu G, Attini R, et al. Risk of adverse pregnancy outcomes in women with CKD. JASN. 2015;26:2011-2022.

21. Zhang JJ, Ma XX, Hao L, Liu LJ, Lv JC, Zhang H. A systematic review and meta-analysis of outcomes of pregnancy in $\mathrm{CKD}$ and $\mathrm{CKD}$ outcomes in pregnancy. CJASN. 2015;10:1964-1978.

22. Imbasciati E, Gregorini G, Cabiddu G, et al. Pregnancy in CKD stages 3 to 5: fetal and maternal outcomes. Am J Kidney Dis. 2007;49: $753-762$.

23. Limardo M, Imbasciati E, Ravani P, et al. Pregnancy and progression of IgA nephropathy: results of an Italian multicenter study. Am J Kidney Dis. 2010;56:506-512.

24. Jones DC, Hayslett JP. Outcome of pregnancy in women with moderate or severe renal insufficiency. NEJM. 1996;335:226-232.

25. Tong A, Brown MA, Winkelmayer WC, Craig JC, Jesudason S. Perspectives on pregnancy in women with CKD: a semistructured interview study. Am J Kidney Dis. 2015;66:951-961.

26. Kendrick J SS, Holmen J, Palit S, Nuccio E, Chonchol M. Kidney disease and maternal and fetal outcomes in pregnancy. Am J Kidney Dis. 2015;66:55-59.

27. Alsuwaida A, Mousa D, Al-Harbi A, Alghonaim M, Ghareeb S, Alrukhaimi MN. Impact of early chronic kidney disease on maternal and fetal outcomes of pregnancy. J Matern Fetal Neonatal Med. 2011;24: 1432-1436.

28. You JY, Kim MK, Choi SJ, et al. Predictive factors for adverse pregnancy outcomes after renal transplantation. Clin Transplant. 2014;28: 699-706.

29. Smyth A, Oliveira GH, Lahr BD, Bailey KR, Norby SM, Garovic VD. A systematic review and meta-analysis of pregnancy outcomes in patients with systemic lupus erythematosus and lupus nephritis. CJASN. 2010;5:2060-2068.

30. Castellano G, Losappio V, Gesualdo L. Update on pregnancy in chronic kidney disease. Kidney Blood Press Res. 2011;34:253-260.

31. Stanhope TJ, White WM, Moder KG, Smyth A, Garovic VD. Obstetric nephrology: lupus and lupus nephritis in pregnancy. CJASN. 2012;7: 2089-2099. 
32. Wu M, Wang D, Zand L, et al. Pregnancy outcomes in autosomal dominant polycystic kidney disease: a case-control study. J Matern Fetal Neonatal Med. 2016;29:807-812.

33. Chauveau D, Fakhouri F, Grunfeld JP. Liver involvement in autosomaldominant polycystic kidney disease: therapeutic dilemma. JASN. 2000; 11:1767-1775.

34. Vora N, Perrone R, Bianchi DW. Reproductive issues for adults with autosomal dominant polycystic kidney disease. Am J Kidney Dis. 2008; 51:307-318.

35. Piccoli GB, Pia A, Vigotti F, et al. Autosomal dominant polycystic kidney disease: what do we need to know for counselling? EMJ Neph. 2014;2(1):51-60.

36. Bramham K, Rajasingham D. Pregnancy in diabetes and kidney disease. J Ren Care. 2012;38(Suppl 1):78-89.

37. Piccoli GB, Clari R, Ghiotto S, et al. Type 1 diabetes, diabetic nephropathy, and pregnancy: a systematic review and meta-study. Rev Diabet Stud. 2013;10:6-26.

38. Bell R, Glinianaia SV, Tennant PW, Bilous RW, Rankin J. Periconception hyperglycaemia and nephropathy are associated with risk of congenital anomaly in women with pre-existing diabetes: a populationbased cohort study. Diabetologia. 2012;55:936-947.

39. Bramham K, Lightstone L. Pre-pregnancy counseling for women with chronic kidney disease. J Nephrol. 2012;25:450-459.

40. Wiles KS, Bramham K, Vais A, et al. Pre-pregnancy counselling for women with chronic kidney disease: a retrospective analysis of nine years' experience. BMC Nephrol. 2015;16:28.

41. Webster P, Wardle A, Bramham K, Webster L, Nelson-Piercy C, Lightstone L. Tacrolimus is an effective treatment for lupus nephritis in pregnancy. Lupus. 2014;23:1192-1196.

42. Bramham K, Lightston L. Preconceptual counseling for women with chronic kidney disease. In: Karoshi MNS, B-Lynch C, Keith L, editors. A Textbook of Preconceptual Medicine and Management. Carlisle: Sapiens Publishing Ltd; 2012.

43. Australian Department of Health [Internet]. Clinical Practice Guidelines-Antenatal Care; 2013. Available from: http://www.health. gov.au/internet/publications/publishing.nsf/Content/clinical-practiceguidelines-ac-mod $1 \sim$ part-b chromosomal-abnormalities $\sim$ background. Accessed December 27, 2015

44. ACOG Practice Bulletin No 77: screening for fetal chromosomal abnormalities. Obstet Gynecol. 2007;109(1):217-227.

45. Benachi A, Dreux S, Kaddioui-Maalej S, et al. Down syndrome maternal serum screening in patients with renal disease. Am J Obstet Gynecol. 2010;203:60e1-4

46. Shulman LP, Briggs R, Phillips OP, Friedman SA, Sibai B. Renal hemodialysis and maternal serum triple analyte screening. Fetal Diagn Ther. 1998; 13:26-28.

47. Valentin M, Muller F, Beaujard MP, et al. First-trimester combined screening for trisomy 21 in women with renal disease. Prenat Diagn. 2015; 35:244-248.

48. Wittfooth S, Tertti R, Lepantalo M, et al. Studies on the effects of heparin products on pregnancy-associated plasma protein A. Clin Chim Acta. 2011;412:376-381.

49. Bramham K, Parnell B, Nelson-Piercy C, Seed PT, Poston L, Chappell LC. Chronic hypertension and pregnancy outcomes: systematic review and meta-analysis. BMJ. 2014;348:g2301.

50. KDIGO. KDIGO clinical practice guideline for the management of blood pressure in chronic kidney disease. Kidney Int Suppl. 2012;2(5):337-414.

51. von Dadelszen P, Ornstein MP, Bull SB, Logan AG, Koren G, Magee LA. Fall in mean arterial pressure and fetal growth restriction in pregnancy hypertension: a meta-analysis. Lancet. 2000;355:87-92.

52. Magee LA, von Dadelszen $P$, Rey E, et al. Less-tight versus tight control of hypertension in pregnancy. NEJM. 2015;372:407-417.

53. SOMANZ [Internet]. Guideline for the Management of Hypertensive Disorders of Pregnancy; 2014. Available from: https://somanz.org/documents/HTPregnancyGuidelineJuly2014.pdf. Accessed October 18, 2015.

54. Hypertension in Pregnancy: The Management of Hypertensive Disorders in Pregnancy - NICE Clinical Guidelines. London: Royal College of Obstetricians and Gynaecologists; 2011.
55. Hypertension in Pregnancy. Washington: American Congress of Obstetricians and Gynaecologists; 2013.

56. Cooper WO, Hernandez-Diaz S, Arbogast PG, et al. Major congenital malformations after first-trimester exposure to ACE inhibitors. NEJM. 2006;354:2443-2451.

57. Li DK, Yang C, Andrade S, Tavares V, Ferber JR. Maternal exposure to angiotensin converting enzyme inhibitors in the first trimester and risk of malformations in offspring: a retrospective cohort study. BMJ. 2011;343:d5931.

58. Piccoli GB, Cabiddu G, Attini R, et al. Pregnancy in CKD: questions and answers in a changing panorama. Best Pract Res Clin Obstet Gynaecol. 2015;29(5):625-642.

59. NICE[Internet]. NICEClinical Guidance 107-Hypertension in Pregnancy; 2010. Available from: www.nice.org.uk. Accessed October 18, 2015.

60. Duley L, Henderson-Smart DJ, Meher S, King JF. Antiplatelet agents for preventing pre-eclampsia and its complications. Cochrane Database Syst Rev. 2007;2:CD004659.

61. Rolfo A, Attini R, Tavassoli E, et al. Is it possible to differentiate chronic kidney disease and preeclampsia by means of new and old biomarkers? A prospective study. Dis Markers. 2015;2015:127083.

62. Khalil A, Cowans NJ, Spencer K, Goichman S, Meiri H, Harrington K. First trimester maternal serum placental protein 13 for the prediction of pre-eclampsia in women with a priori high risk. Prenat Diagn. 2009;29: 781-789.

63. Chappell LC, Bramham K, Shennan AH. Short-term prediction of preeclampsia: how close are we? Biomark Med. 2014;8:455-458.

64. Thangaratinam S, Coomarasamy A, O'Mahony F, et al. Estimation of proteinuria as a predictor of complications of pre-eclampsia: a systematic review. BMC Med. 2009; 7:10.

65. Luders C, Castro MC, Titan SM, et al. Obstetric outcome in pregnant women on long-term dialysis: a case series. Am J Kidney Dis. 2010;56: 77-85.

66. Saliem S, Patenaude V, Abenhaim H. Pregnancy outcomes among renal transplant recipients and patients with end-stage renal disease on dialysis. J Perinat Med. 2016;44(3):321-327.

67. Piccoli GB, Cabiddu G, Daidone G, et al. The children of dialysis: live-born babies from on-dialysis mothers in Italy - an epidemiological perspective comparing dialysis, kidney transplantation and the overall population. Nephrol Dial Transplant. 2014;29:1578-1586.

68. Cabiddu G, Castellino S, Gernone G, et al. Best practices on pregnancy on dialysis: the Italian Study Group on Kidney and Pregnancy. J Nephrol. 2015;28:279-288.

69. Hladunewich MA, Hou S, Odutayo A, et al. Intensive hemodialysis associates with improved pregnancy outcomes: a Canadian and United States cohort comparison. JASN. 2014;25:1103-1109.

70. Alkhunaizi A, Melamed N, Hladunewich MA. Pregnancy in advanced chronic kidney disease and end-stage renal disease. Curr Opin Nephrol Hypertens. 2015;24:252-259.

71. Barua M, Hladunewich M, Keunen J, et al. Successful pregnancies on nocturnal home hemodialysis. CJASN. 2008;3:392-396.

72. Asamiya Y, Otsubo S, Matsuda Y, et al. The importance of low blood urea nitrogen levels in pregnant patients undergoing hemodialysis to optimize birth weight and gestational age. Kidney Int. 2009;75:1217-1222.

73. Craig KL, Podymow T, Pauly RP. Intensifying renal replacement therapy during pregnancy: the role for nocturnal home hemodialysis. Int Urol Nephrol. 2009;42:137-139.

74. Piccoli GB, Minelli F, Versino E, et al. Pregnancy in dialysis patients in the new millennium: a systematic review and meta-regression analysis correlating dialysis schedules and pregnancy outcomes. Nephrol Dial Transplant. Epub 2015 Nov 27.

75. Jefferys A, Wyburn K, Chow J, Cleland B, Hennessy A. Peritoneal dialysis in pregnancy: a case series. Nephrology. 2008;13:380-383.

76. Wyld ML, Clayton PA, Jesudason S, Chadban SJ, Alexander SI. Pregnancy outcomes for kidney transplant recipients. Am J Transplant. 2013; 13:3173-3182.

77. Wyld ML, Clayton PA, Kennedy S, Alexander SI, Chadban SJ. Pregnancy outcomes for kidney transplant recipients with transplantation as a child. JAMA. 2015;169:1-6. 
78. Norrman E, Bergh C, Wennerholm UB. Pregnancy outcome and long-term follow-up after in vitro fertilization in women with renal transplantation. Human Reprod. 2015;30:205-213.

79. McKay DB, Josephson MA, Armenti VT, et al. Reproduction and transplantation: report on the AST Consensus Conference on Reproductive Issues and Transplantation. Am J Transplant. 2005;5:1592-1599.

80. KDIGO. KDIGO clinical practice guideline for the care of kidney transplant recipients. Am J Transplant. 2009;9(Suppl 3):S1-S155.

81. Arab K, Oddy L, Patenaude V, Abenhaim H. Obstetrical and neonatal outcomes in renal transplant recipients. J Matern Fetal Neonatal Med. 2015; 28(2):162-167.

82. Armenti V, Constantinescu S, Moritz M, Davison J. Pregnancy after transplantation. Transplant Rev. 2008:223-240.

83. Blume C, Pischke S, von Versen-Hoynck F, Gunter HH, Gross MM. Pregnancies in liver and kidney transplant recipients: a review of the current literature and recommendation. Best Pract Res Clin Obstet Gynaecol. 2014;28:1123-1136.

84. Bramham K, Nelson-Piercy C, Gao H, et al. Pregnancy in renal transplant recipients: a UK national cohort study. CJASN. 2013;8:290-298.

85. Deshpande N, James N, Kucirka L, et al. Pregnancy outcomes in kidney transplant recipients: a systematic review and meta-analysis. $\mathrm{Am} \mathrm{J}$ Transplant. 11:2388-2404.

86. McKay DB, Josephson MA. Pregnancy in recipients of solid organs effects on mother and child. NEJM. 2006;354:1281-1293.

87. Sibanda N, Briggs J, Davison J. Pregnancy after organ transplantation: a report from the U.K. Transplant Pregnancy Registry. Transplantation. 2007;83:1301-1307.

88. Hebral A, Cointault O, Connan L, et al. Pregnancy after kidney transplantation: outcome and anti-human leucocyte antigen alloimmunization risk. Nephrol Dial Transplant. 2014;29(9):1786-1793.

89. Deshpande NA, Coscia LA, Gomez-Lobo V, Moritz MJ, Armenti VT. Pregnancy after solid organ transplantation: a guide for obstetric management. Rev Obstet Gynecol. 2013;6:116-125.

90. Josephson MA, McKay DB. Women and transplantation: fertility, sexuality, pregnancy, contraception. Adv Chronic Kidney Dis. 2013;20: 433-440.

91. Kim H, Seok H, Kim TH, Han DJ, Yang WS, Park SK. The experience of pregnancy after renal transplantation: pregnancies even within postoperative 1 year may be tolerable. Transplantation. 2008;85:1412-1419.

92. Kim H, Jeong J, Yang W, et al. The optimal therapy of calcineurin inhibitors for pregnancy in kidney transplantation. Clin Transplant. 2015; 29:142-148.

93. Hebert MF, Zheng S, Hays K, et al. Interpreting tacrolimus concentrations during pregnancy and postpartum. Transplantation. 2013;95:908-915.

94. Kim M, Rostas S, Gabardi S. Mycophenolate fetal toxicity and risk evaluation and mitigation strategies. Am J Transplant. 2013;13:1383-1389.

95. Framarino-dei-Malatesta M, Derme M, Napoli A, et al. Placental, lipid, and glucidic effects of mammalian target of rapamycin inhibitors: impact on fetal growth and metabolic disorders during pregnancy after solid organ transplantation. Transplant Proc. 2014;46:2254-2258.
96. Turan OM, Turan S, Gungor S, et al. Progression of Doppler abnormalities in intrauterine growth restriction. Ultrasound Obstet Gynecol. 2008;32:160-167.

97. Oros D, Figueras F, Cruz-Martinez R, MelerE, Munmany M, Gratacos E. Longitudinal changes in uterine, umbilical and fetal cerebral Doppler indices in late-onset small-for-gestational age fetuses. Ultrasound Obstet Gynecol. 2011;37:191-195.

98. Broekhuijsen K, van Baaren GJ, van Pampus MG, et al. Immediate delivery versus expectant monitoring for hypertensive disorders of pregnancy between 34 and 37 weeks of gestation (HYPITAT-II): an openlabel, randomised controlled trial. Lancet. 2015;385:2492-2501.

99. Thiagarajan K, Arakali S, Mealey K, et al. Safety considerations: breastfeeding after transplant. Prog Transplant. 2013;23:137-146.

100. Constantinescu S, Pai A, Coscia L, Davison J, Moritz M, Armenti V. Breast-feeding after transplantation. Best Pract Res Clin Obstet Gynaecol. 2014;28(8):1163-1173.

101. Bramham K, Chusney G, Lee J, Lightstone L, Nelson-Piercy C. Breastfeeding and tacrolimus: serial monitoring in breast-fed and bottle-fed infants. CJASN. 2013;8:563-567.

102. Watnick S. Pregnancy and contraceptive counseling of women with chronic kidney disease and kidney transplants. Adv Chronic Kidney Dis. 2007;14:126-131.

103. Paulen ME, Folger SG, Curtis KM, Jamieson DJ. Contraceptive use among solid organ transplant patients: a systematic review. Contraception. 2010;82:102-112.

104. Faculty of Sexual and Reproductive Healthcare, Royal College of Obstetricians and Gynaecologists [Internet]. UK Medical Eligibility Criteria for Contraceptive Use; 2016. Available from: https://www. fsrh.org/documents/ukmec-2016/. Accessed June 92016.

105. Mittal S, Aggarwal P, Dadhwal V. Medical abortion in women with impaired renal function. Int J Gynaecol Obstet. 2011;114:76-77.

106. Tong A, Jesudason S, Craig JC, Winkelmayer WC. Perspectives on pregnancy in women with chronic kidney disease: systematic review of qualitative studies. Nephrol Dial Transplant. 2015;30:652-661.

107. National Kidney Foundation [Internet]. NKF KDOQI Guidelines; 2002. Available from: http://www2.kidney.org/professionals/KDOQI/ guidelines_ckd/p4_class_g1.htm. Accessed October 4, 2015.

108. Sifontis NM, Coscia LA, Constantinescu S, Lavelanet AF, Moritz MJ, Armenti VT. Pregnancy outcomes in solid organ transplant recipients with exposure to mycophenolate mofetil or sirolimus. Transplantation. 2006;82:1698-1702.

109. Tendron A, Gouyon JB, Decramer S. In utero exposure to immunosuppressive drugs: experimental and clinical studies. Pediatr Nephrol. 2002; $17: 121-130$.
International Journal of Women's Health

\section{Publish your work in this journal}

The International Journal of Women's Health is an international, peerreviewed open-access journal publishing original research, reports, editorials, reviews and commentaries on all aspects of women's healthcare including gynecology, obstetrics, and breast cancer. The manuscript management system is completely online and includes

\section{Dovepress}

a very quick and fair peer-review system, which is all easy to use. Visit http://www.dovepress.com/testimonials.php to read real quotes from published authors. 